\title{
Effective Tools and Strategies to Promote Academic Integrity in e-Learning
}

\author{
Suhansa Rodchua* \\ TRG318D, School of Technology, University of Central Missouri, Warrensburg, MO, USA. \\ * Corresponding author. Tel.: 660-543-4438; email: rodchua@ucmo.edu \\ Manuscript submitted February 5, 2017; accepted March 23, 2017. \\ doi: 10.17706/ijeeee.2017.7.3.168-179
}

\begin{abstract}
Academic integrity is one of the fundamental values that institutions must commit to uphold and to promote. This core principle is a foundation of students' achievement and growth and it also leads to good citizenship and the betterment of our society. With progressing technological tools and widely connecting of worldwide web, students can now plagiarize and cheat on their assignments with more ease. Student verification is another important issue of distance education to confirm that the person participating and receiving credits for the course is the student enrolling and doing the work. The number of university students who admit to cheating in some form is immense, and this dishonest conduct can damage schools' reputation and students' learning experience.

The purpose of this study is to present effective tools and strategies used in student verification and assessment quality assurance. This paper comprises of current technology used as remote proctoring systems to verify students' identification, plagiarism software to compare students' assignments to massive databases, and applications to lockdown browsers while students take exams. The author conducted a mix of experimental and historical study by gathering data of 284 research papers using SafeAssign to check percentage (\%) of matching. These papers were from 260 senior undergraduate and graduate students in the School of Technology between years 2011-2016. The Statistical Package for Social Science (SPSS) version 23.0 and Paired Samples T-test were utilized to test significant difference between variables at 95\% of confidence level.

Effective tools and strategies that can be used in online course development and delivery to promote academic integrity and quality assurance are assessment diversity, written assignment and threads, student verification system, plagiarism software, and lockdown browsers.
\end{abstract}

Key words: Academic integrity, plagiarism, quality assurance, SafeAssign, student verification.

\section{Introduction}

Why are online student verification and plagiarism detection becoming major challenges in this information technology era? Continued growth in distance learning and the inability to control the student's environment is an elevated concern to institutions of higher education. According to the study from Dr. McCabe and the International Center for Academic Integrity, data from 71,300 undergraduate and 17,000 graduate students show that $68 \%$ of undergraduate students admit to written or test cheating and $43 \%$ of graduate students [1]. The number of university students who admit to cheating in some forms is immense, and this dishonest conduct can damage schools' reputations and students' learning experiences. Issues of academic integrity ought to be considered by every level of involved stakeholders including government, 
schools, and business organizations.

The US Higher Education Opportunity Act, verbiage in Public Law 11-315, "directs accreditation agencies to require an institution to have processes to establish that the student who registers in a distance education course or program is the same student who participates in and completed the program and receives the academic credits" [2], [3, para. 2]. There are many reasons to verify online students while they access the course and take an exam. According to [4], the issues that mandate universities and college to authenticate student and their work are institutional credibility, federal requirements, accreditation requirements, and student achievement.

What are effective tools and techniques used in promoting academic integrity? Business enterprises have developed a number of applications and devices to verify student identity and to detect plagiarism in assignments. In, "5 Ways Online Education Can Keep Its Students Honest", Heussner presents the five high-tech tools digital learning platforms that can help to keep students honest. These 5 ways are 1) remote live proctoring (e.g. ProctorCam, ProctorU, and Remote Proctor Now), 2) remote web proctoring (e.g. McGraw-Hill's Integrity division and Kryterion), 3) browser lockdowns (Respondus), 4) keystroke pattern recognition software, and 5) plagiarism detection software (e.g. TurnItIn, SafeAssign) [5]. The major topics covered in this research paper are

- Different systems of remote proctoring examination

- Effective tools and strategies used in student identification, quality assignments design and development, and students taking online exams.

- Research hypotheses compares the percentage matching from SafeAssign software: domestic-international students, male-female, and 8 week - 16 week semesters.

\section{Purpose and Significance of the Study}

The purpose of this study is to present effective tools and strategies used in student verification and assessment quality assurance. This paper comprises of current technology used as remote proctoring systems to verify students' identification, plagiarism software to compare students' assignments to massive databases, and lockdown browsers for students taking exams. The author gathered 284 research papers using SafeAssign check the percent of matching text. These papers were from 260 senior undergraduate and graduate students in the School of Technology between years 2011-2016 and they were used for testing the research hypotheses.

Research Questions and Hypotheses

This study proposes 3 primary research questions:

1) What tools and strategies can be used in promoting academic integrity in higher education?

2) What is the average of the percent matching text in research papers checked using SafeAssign software of college students?

3) Are there significant differences on percent matching text in research papers between these 3 pairs: domestic and international students, male and female students, and students enrolled in 8-week and 16-week semesters?

To answer research question 3, the following three null hypotheses are posed:

Ho1: There is no significant difference on the percent (\%) of matching text between research paper of domestic and international students.

Ho2: There is no significant difference on the percent (\%) of matching text between research paper of male and female students.

Ho3: There is no significant difference on the percent (\%) of matching text between research paper of students enrolled in 8 week and 16 week semesters. 
The findings of this study and previous research are used to establish an effective model of online course delivery. Key components that can be used in distance learning to promote academic integrity and quality assurance are administration and technical supports, student engagement, instructional and design strategies, technological tools and software.

\section{Review of Literature}

The focus of this review of literature is on current technology and methods used in promoting academic integrity which include student identity verification, lockdown browsers, and assignment plagiarism detection. Robin (2015) states that issues of academic integrity ought to be considered during the design, delivery, and redesign of courses, in particular those with an online component [6]. Reference to [3] discuss online learner authentication as one of major issues in academic integrity policies which can be managed by faculty and academic leaders. This study also mentions fraud in academia that may include three recognized conditions known as the "Fraud Triangle". This fraud triangle include an opportunity, an incentive or reward, and a rationalization [7]. Furthermore, a study of 476 business students shows that:

When each element of the fraud triangle is reduced, the result is a significant determinant in student cheating [8]. The results of another study suggest that $73.6 \%$ of the students in the sample held the perception that it is easier to cheat in an online versus traditional course [9], [3, para. 6].

The latest techniques used to verify that a person participating in the course is the student who is enrolled in the courses includes challenge questions, video capture, biometrics, and proctoring software [4]. This section will discuss the major technology used in these 3 areas:

\subsection{Identification and Proctoring Systems}

Today technology allows the online proctoring system to utilize the software, hardware, fingerprint scanners, video monitoring personnel, and other technologies to identify the online students and monitor them while taking exams without commuting to the proctor locations [10]. Some examples of providers of the remote proctors discussed in this section are:

1) Securexam Remote Proctor (SRP) - addresses are areas of exam security by authenticating the student with a fingerprint scanner prior to providing access to the exam, restricting the computer's functions with Secureexam solution, and monitoring with video and audio during the exam. According to the Office of University Relations Media, Troy University, SRP equipment will cost students about $\$ 125$. This system also records the test-taker's voice and image through a camera that records 360-degree real-time video and audio of the environment during the entire exam. All suspicious sound, activity, and motion are catalogued during the recording, limiting the need for constant monitoring.

2) ProctorU - is a commercial software developed by Andrew Jackson University and spun off into a separate company. Jarrod Morgan, co-developer of Proctor, stated "We have improved the system by adding live certified proctors, real time audio/video using TokBox, technical assistance, practice exams, identify authentication and the ability to assist exam-takers by remotely controlling their computers during an exam" [11, para. 1].

3) ProctorCam - is a business and system that provides a virtual online proctoring service. The company has developed a software-enabled online exam proctoring service for online course publishers. Remote proctors, average US $\$ 20$ per hour, hired under contract by the fledgling company, monitor students and answer their questions via webcams [12]. To use ProctorCam, the system integrates desktop sharing software, a web cam, a microphone and a reliable internet connection.

4) Webassesor ${ }^{\mathrm{TM}}$ - from Kryterion Inc. specializes in secure test development and delivery. They provide live proctoring for many distance learning and businesses [13]. The Webassesor ${ }^{\mathrm{TM}}$ is capable of 
online proctoring via webcams with audio features to monitor test takers.

In addition, biometrics has become a vital method of ensuring security against threats such as theft and malicious intents in this era of globalization. It involves the identification of an individual based on one or more unique physical attribute. Biometric identification can be physiological such as fingerprint, retina, and DNA; it can be behavioral such as handwriting, gait, and/or speech pattern. A biometric method is evaluated based on specific qualities including its universality, uniqueness, permanence, collectability, performance, acceptability and circumvention [10], [14].

Table 1. Different Systems in Student Identification and Exam Proctoring

\begin{tabular}{|c|c|c|}
\hline Systems & Description & Purpose \\
\hline $\begin{array}{l}\text { Secureexam Remote Proctor (SRP) } \\
\text { http://www.remoteproctor.com }\end{array}$ & $\begin{array}{l}\text { Fingerprint for student identification, video surveillance } \\
\text { system /audio recording with SRP device. } \\
\text { Cost: } \$ 125 \text { for SRP equipment and } \$ 30 \text { annual fee }\end{array}$ & $\begin{array}{l}\text { Student } \\
\text { identification } \\
\text { and proctoring }\end{array}$ \\
\hline $\begin{array}{l}\text { ProctorU } \\
\text { http://www.proctoru.com } \\
\text { (virtual online proctoring) }\end{array}$ & $\begin{array}{l}\text { Username - password, and ID photo for student } \\
\text { identification, human proctor in real-time and video } \\
\text { surveillance system /audio recording } \\
\text { Cost: } \$ 17.50 \text { per } 2 \text { hours exam }\end{array}$ & $\begin{array}{l}\text { Student } \\
\text { identification } \\
\text { and proctoring }\end{array}$ \\
\hline $\begin{array}{l}\text { ProctorCam } \\
\text { http://www.proctorcam.com } \\
\text { (virtual online proctoring) }\end{array}$ & $\begin{array}{l}\text { Username - password, and ID photo for student } \\
\text { identification, human proctor in real-time and video } \\
\text { surveillance system /audio recording } \\
\text { Cost: average } \$ 20 \text { per } 1 \text { hour exam, discount on the group } \\
\text { of students }\end{array}$ & $\begin{array}{l}\text { Student } \\
\text { identification } \\
\text { and proctoring }\end{array}$ \\
\hline Webassesor ${ }^{\mathrm{TM}}$ & $\begin{array}{l}\text { Facial recognition software and patterns of keystroke } \\
\text { rhythms, secure Browser Control, and video surveillance } \\
\text { system } \\
\text { Cost: Webcam } \$ 50-\$ 80 \text { plus costs of application }\end{array}$ & $\begin{array}{l}\text { Student } \\
\text { identification } \\
\text { and proctoring }\end{array}$ \\
\hline $\begin{array}{l}\text { SafeAssign } \\
\text { (Integrated into Blackboard) }\end{array}$ & $\begin{array}{l}\text { Integrated into Blackboard, comparing students' } \\
\text { submissions to databases of millions of student papers, } \\
\text { articles and Websites } \\
\text { Cost: included in annual Blackboard cost }\end{array}$ & $\begin{array}{l}\text { Plagiarism } \\
\text { detection } \\
\text { software }\end{array}$ \\
\hline TurnItIn & $\begin{array}{l}\text { Internet-based plagiarism-prevention service } \\
\text { Cost: institutional subscriptions cost } 87 \text { cents per student } \\
\text { annually [15]. }\end{array}$ & $\begin{array}{l}\text { Plagiarism } \\
\text { detection } \\
\text { software }\end{array}$ \\
\hline Lockdown browser from Respondus & $\begin{array}{l}\text { Locks down the testing environment within a learning } \\
\text { management system } \\
\text { Cost: campus-wide pricing, } \$ 3,545 \text { for } 2,501-5,000 \\
\text { students [16] }\end{array}$ & $\begin{array}{l}\text { Lockdown } \\
\text { Browser }\end{array}$ \\
\hline KioWare Kiosk system & $\begin{array}{l}\text { Lockdown security for browser based applications } \\
\text { Cost: individual license prices varied, } \$ 135 \text { for KioWare } \\
\text { Basic for Window [21] }\end{array}$ & $\begin{array}{l}\text { Lockdown } \\
\text { Browser }\end{array}$ \\
\hline
\end{tabular}

\subsection{Plagiarism Detection Software}

The two dominant technologies for plagiarism detection in academic institutions are SafeAssign and TurnItIn. These two applications can compare students' submissions to databases of millions of student papers, articles, and websites [15]. The grader will receive a report on the similarity of that assignment to everything else in the database. It is up to the grader's judgment to figure out whether the similarities actually constitute plagiarism or are just the unavoidable similarities that a search of millions of documents can find. Also graders can then comment on and evaluate assignments within the plagiarism detection applications [15].

1) SafeAssign - is a tools used to promote originality and to create opportunities to help students identify how to properly attribute sources rather than paraphrase [16]. How SafeAssign works?

SafeAssign is based on a unique text-matching algorithm capable of detecting exact and inexact matching between a submitted paper and source material. This proprietary algorithm analyzes submission text and optimizes the words and terms to be searched against multiple data sources. Results returned from each 
service are further processed based on both the weight returned by the search service and comparative weighting by the SafeAssign algorithm, which determines the result set to be returned in the originality report [16, para.3].

2) TurnItIn - is an internet-based plagiarism-prevention service created by iParadigms, LLC. The schools buy licenses to submit essays to the TurnItIn website. TurnItIn checks the documents for unoriginal content by comparing submitted papers to several databases using a proprietary algorithm. It scans its own databases and also has licensing agreements with large academic proprietary databases [17]. According to Florida Atlantic University (2016), "TurnItIn includes some additional features that are not available in SafeAssign, such as Grade mark, an online paperless grading, rubric and feedback tool, and Peer Mark, a tool that facilitates peer review so that students can evaluate each other's work anonymously" [18, para. 1].

\subsection{Lockdown Browser}

1) The LockDown browser from Respondus is a custom browser that locks down the testing environment within a learning management system. Students are unable to copy, print, access other applications, or visit other websites during an online exam [19].

2) KioWare Kiosk system provides vital lockdown security for browser based applications, restricting users from accessing the operating system and desktop, and limiting internet access to only allowed websites [20].

Table 1 presents the different systems, descriptions, costs, and purposes of the current applications used for promoting academic integrity. Part of data in Table 1 is adapted from the author's previous study, title "Student verification system for online assessments: bolstering quality and integrity of distance learning" [10].

\section{Methodology}

The research population included 284 research papers uploaded into the SafeAssign in Blackboard between years 2011-2016. These papers were from 260 senior undergraduate and graduate students in the School of Technology enrolled in 4 different courses: IndM 4010 (Current issues in industry), IndM 4260 (Organizational Dynamics), IndM 5230 (Seminar in Industrial Management), and IndM 6580 (Advance Strategic Quality Standard). This study used the \% matching of each paper, then identified and divided them into 7 groups: domestic students, international students, male, female, 8 week semester, 16 week semester, and group project. An Excel spreadsheet was used in coding and analyzing preliminary data. The Statistical Package for Social Science (SPSS) version 23.0 and Paired Samples T-test were utilized to test significant relationship between variables. The .05 alpha, or $95 \%$ of confidence level, was established to determine whether the observed value was significantly different from the expected value.

The main instrument used in this study is the SafeAssign software, which is used for comparing submitted assignments against a set of sources to identify areas of overlap between the submitted assignment and existing works. According to Blackboard, "SafeAssign is a tool used to promote originality and to create opportunities to help students identify how to properly attribute sources rather than paraphrase. Safe Assign is effective as both a deterrent and an educational tools" [22, para.1]. Work or assignment submissions to SafeAssign are compared against several sources, such as institutional document archives, global reference database, ProQuest journal Database, and Internet. It searches across the broader world wide web for matching text using an internal search service. After the search, SafeAssign will present the results (document file name, name of the checker with date and time of submission, text in documents with highlight different colors and the original sources, numbers of sources and the percent of matching or copying), as shown in Fig. 1. 


\subsection{Limitations of the Study}

The experimental part of this study is limited to data gathered from students' research papers in percent (\%) of matching with SafeAssign software from Blackboard Inc. The results returned in a SafeAssign may not be $100 \%$ correct and accurate due to the ever-changing nature of the internet and the combination of search index characteristics and the weighting applied by the SafeAssign algorithm [22]. The findings were acquired from senior undergraduate and graduate students in industrial management courses. This may not be generalizable to other programs (such as education, arts and mass communication) and to other levels of education. Each type of target population group has characteristics (such as culture, time period of study and ages) that may cause differences in following rules of writing research papers.
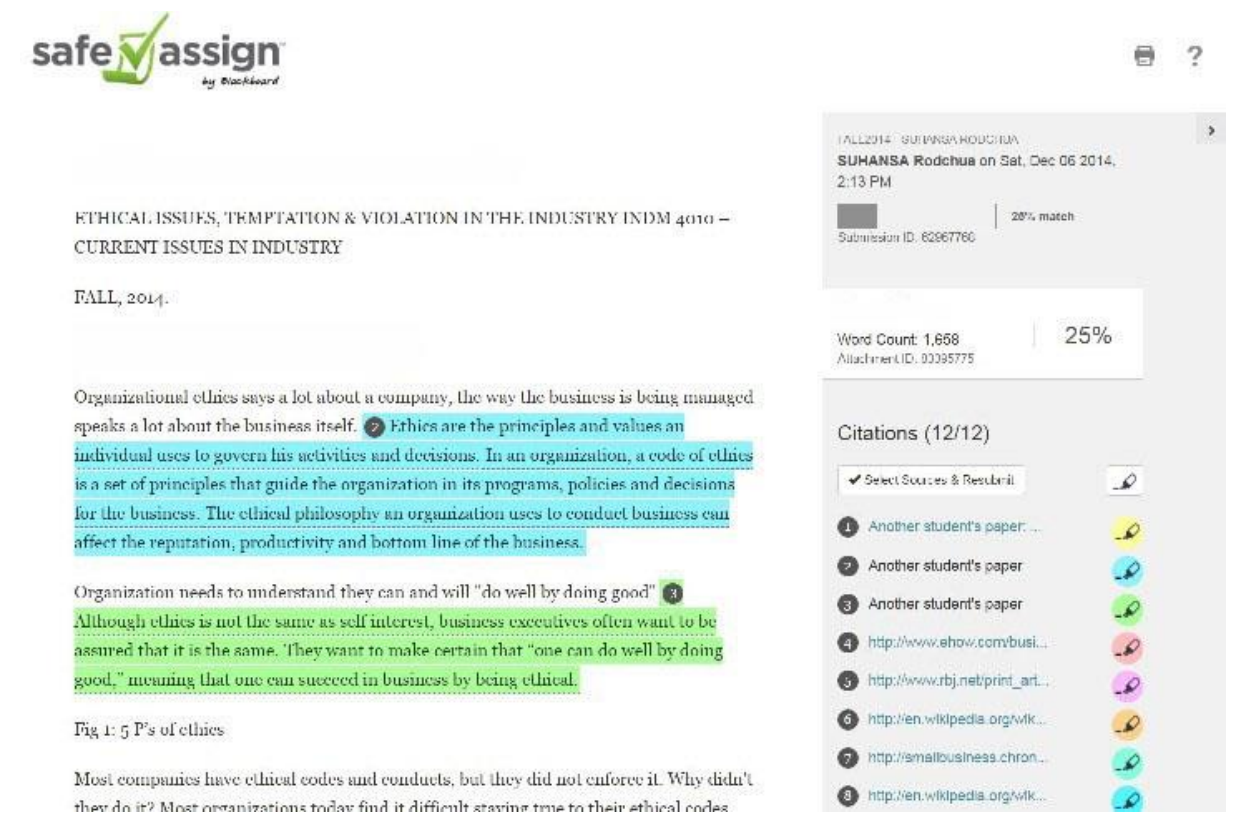

Fig. 1. Checking assignment with SafeAssign in blackboard.

\section{Finding and Data Analysis}

The finding of this experimental research are divided into two major sections: 1) demographic and descriptive statistics of the population, and 2) testing research hypotheses.

\subsection{Demographic and Descriptive Statistics}

The study results was gathered from 284 research papers in 4 different courses offered between 2011-2016. With the purpose of finding the difference between the groups and the level of copying for each population group, there are 7 groups:

1) Domestic students - majority are Americans, working full-time, studying on-line, and about 25-50 years of age.

2) International students - most are foreigners, studying full-time, might working on campus (5-20 hours a week), and about 22-35 years of age.

3) Male - male students enrolled in the program

4) Female - female students enrolled in the program

5) 8 weeks summer courses - the summer course is 8 weeks long offering between June 1-July 25.

6) 16 weeks Spring and Fall courses - the course in Spring or Fall semester is 16 weeks long

7) Research paper in group project - about 3-6 students working in a group project, one research paper 
for each group.

The focus on this finding is the \% copying or matching of the paper comparing with the original sources. The higher percent copying can be interpreted that student's work is lack of originality or student has poor knowledge in doing proper citation and writing paper. Table 2 presents the demographic data of the 7 population groups including number of papers, average \% of matching for each group, and number of papers with $100 \%$ matching. Fig. 2 also demonstrates the ranking from low to high average $\%$ of matching of each group.

Table 2. Number of Papers and Average \% of Copying for 8 Population Groups

\begin{tabular}{|c|c|c|c|c|c|c|c|}
\hline & Domestic & Int'l & Male & Female & $\begin{array}{l}8 \text { week } \\
\text { Semester }\end{array}$ & $\begin{array}{l}16 \text { week } \\
\text { Semester }\end{array}$ & $\begin{array}{l}\text { Group } \\
\text { Project }\end{array}$ \\
\hline \multicolumn{8}{|l|}{ Descriptive statistics } \\
\hline Number of papers $(\mathrm{N})$ & 135 & 147 & 229 & 55 & 126 & 158 & 36 \\
\hline Average $\%$ of matching & 15.1 & 29.8 & 20.9 & 18.7 & 23.6 & 21.8 & 15.8 \\
\hline Std. Deviation & 18.3 & 31.1 & 24.4 & 24.3 & 27.1 & 26.5 & 14.9 \\
\hline $\begin{array}{l}\text { \# of papers } 100 \% \\
\text { matching }\end{array}$ & 1 & 13 & 6 & 2 & 6 & 8 & 0 \\
\hline
\end{tabular}

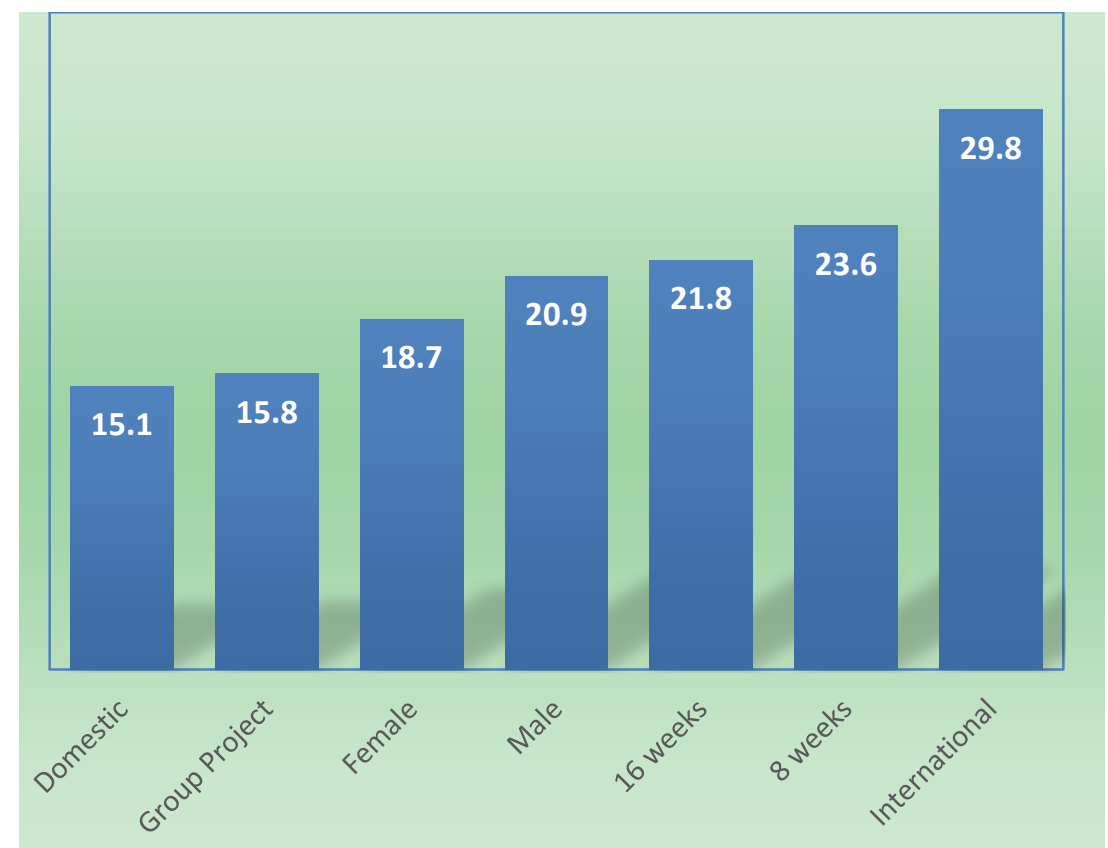

Fig. 2. Average $\%$ of matching of seven groups, ranking from low-high.

Table 2 and Fig. 2 show that domestic students best perform on writing paper and formatting citation with $15.1 \%$ and the lowest group is international students with $29.8 \%$. The average of $\%$ matching of all these 6 groups or 260 college students (not including group project) is $21.7 \%$. The group project shows 15.8\%. Appendix shows Histograms presenting the frequency of all papers for six target population.

Furthermore, the data analysis shows the frequency and cumulative percentage of matching of target population. Traditionally, higher education assesses the grading rubric for student performance evaluation with five levels; A (very good), B (good), C (average), D (below average), and F (failure). To follow traditional grading rubric, this study also evaluates the level of $\%$ matching and divides into 5 grade levels: 
A (0-10\%, very good work), B (11-20\%, good work), C (21-30\%, average), D (31-40\%, below average), and F (above 41\%, failure). Table 3 presents the grade levels A, B, C, D, and F for all the seven studied groups.

Table 3. Number of Papers and Average \% of Copying for 8 Population Groups

\begin{tabular}{lllllllll}
\hline & & Domestic & Int'l & Male & Female & $\begin{array}{l}8 \text { week } \\
\text { Semester }\end{array}$ & $\begin{array}{c}16 \text { week } \\
\text { Semester }\end{array}$ & $\begin{array}{l}\text { Group } \\
\text { Project }\end{array}$ \\
Grade & $\begin{array}{l}\text { Level of } \\
\text { matching }\end{array}$ & & & & & & & \\
A & $0-10 \%$ & 55.6 & 38.8 & 47.6 & 56.4 & 45.2 & 48.7 & 41.9 \\
B & $11-20 \%$ & 24.4 & 15.6 & 20.5 & 16.3 & 20.7 & 19 & 35.9 \\
C & $21-30 \%$ & 7.4 & 12.3 & 10.1 & 9.1 & 8.7 & 10.8 & 5.5 \\
D & $31-40 \%$ & 5.9 & 7.4 & 7.4 & 3.7 & 6.4 & 6.9 & 5.6 \\
F & above $41 \%$ & 6.7 & 25.9 & 14.4 & 14.5 & 19 & 14.6 & 11.1 \\
\hline
\end{tabular}

From Table 3, female students have the highest numbers of $\mathrm{A}$ grades with $56.4 \%$. The $2^{\text {nd }}$ rank is Domestic students with $55.6 \%$. On contrary, the biggest group with F grade is International students with $25.9 \%$.

\subsection{Testing Research Hypotheses}

Data in this section were from 260 students with 284 research papers which submitted into SafeAssign. The percent matching of research papers was used in the calculation. The Paired Sample T-test was utilized to test research hypotheses one through three to see if there was a significant difference of \% copying in each pair, alpha . 05 or a $95 \%$ confidence level. Pair one is between domestic and international students, pair two is between male and female students; and pair three is between the 8 weeks and 16 weeks course. Table 4 illustrates the calculated T-values, degree of freedom, and significance value.

Table 4. Hypothesis Testing of 3 Pairs with T-Test

\begin{tabular}{lllll} 
& & & & \\
Pair 1 & Domestic - International & -4.674 & $\mathrm{df}$ & Sig. (2-tailed) \\
Pair 2 & Male - Female & .439 & 134 & .000 \\
Pair 3 & 8 weeks - 16 weeks & .638 & 125 & .662 \\
\hline
\end{tabular}

According to Table 4, the calculated T-test and significance values are used in testing hypotheses and the followings are results and data interpretation:

$\mathrm{H} 1$ tests whether there is statistically significant difference on $\%$ of matching in research paper between domestic and international students. In Table 4, an obtained $t$-value $(\mathrm{t})$ of -4.674 , the degrees of freedom, which are 134, and the observed significance level (2-tailed p-value) of the paired t-test is 0.000 . Therefore, the null hypothesis is rejected at the .05 level of confidence in favor of the alternative. Based on the population results, there is a difference on \% of matching in research paper between domestic and international students.

$\mathrm{H} 2$ tests whether there is statistically significant difference on $\%$ of matching in research paper between male and female students. In Table 4, an obtained t-value ( $t$ ) of .439, the degrees of freedom, which are 54, and the observed significance level (2-tailed p-value) of the paired t-test is .662. Therefore, the null hypothesis is not rejected at the .05 level of confidence. Based on the population results, there is a no difference on $\%$ of matching in research paper between male and female students. 
$\mathrm{H} 3$ tests whether there is statistically significant difference on $\%$ of matching in research paper between 8-weeks and 16 weeks semesters. In Table 4, an obtained $t$-value $(t)$ of .638, the degrees of freedom, which are 125, and the observed significance level (2-tailed p-value) of the paired t-test is .525. Therefore, the null hypothesis is not rejected at the .05 level of confidence. Based on the population results, there is a no difference on $\%$ of matching in research paper between 8 week and 16 week semesters.

The results from testing these 3 hypotheses suggest that the domestic students tend to perform better than international students in writing papers and formatting citations. However, there is not much different between male and female students; and between 8-week and 16-week semesters.

\section{Discussion and Conclusion}

To uphold academic integrity and assure quality of online education, the proper use of technology and effective teaching and learning methods are essential elements. This study's finding from the review of literature and experimental study can aid in answering the above 3 research questions.

Question 1 asks what tools and strategies can be used in promoting academic integrity in higher education.

Answer: The current technology, effective tools, and strategies that can be used in promoting academic integrity and assuring quality in online education can be dividing into 4 areas:

1) Identification and proctoring systems may include, but not limited to, Secureexam Remote Proctor (SRP), ProctorU, ProctorCam, Webassesor. To identify individual, biometrics can be physiological such as fingerprint, retina, DNA or behavioral such as handwriting, gait, speech pattern etc.

2) Plagiarism detection software that popularly use in academic institutions are SafeAssign and TurnItIn.

3) Lockdown browsers from Respondus and KioWare companies restrict users from accessing the operating system and desktop, and limiting internet access to only allowed websites

4) Assessment diversity, examples are written assignment and public post (Discussion Board), test banks, exam block random, timed assessment, different types of questions/answers (e.g. multiple choice, matching, essay, multiple answers, fill-in-blank, true/false, and short answers).

Question 2 asks about the average \% matching of checked research paper using SafeAssign software of college students.

Answer: Based on 260 senior undergraduate and graduate students, the average of \% matching is $21.7 \%$. Note that the papers from group project has $15.8 \%$ which tends to be better than individual work, referring to the above Table 2 and Figure 2.

Question 3 asks if there is statistically significant difference on \% matching in research papers between these 3 pairs: domestic and international students, male and female students, and 8-week and 16-week semesters.

Answer: Using T-test and alpha .05 level of confidence, the results show that there is difference on \% matching in research papers between domestic and international students, but no difference between male and female students and between 8-week and 16-week semesters.

The information derived from this study can support online course developers and educators in design course materials and assessment to promote high student performance with honesty. Cheating, plagiarism, and other forms of unethical conduct can all harm institutions' reputation and students' learning experience. Reference to [23] suggest that schools should use techniques such as assessment diversity, test banks and timed assessment, and written assignment and threads in ensuring online students submit their own work. To take advantages of advanced technologies and maximize quality on-line, the researcher recommends the following items: 
- Based on the study's finding, students working as a group tend to do better papers with less \% matching than individual student. The culture and background environment can have impact on international students in writing papers and citing properly. It is important that instructor provides handout supplements in research writing and citing prior to students doing assignments. Instructors should also emphasize to students on using APA style manual or any specific writing guidelines at the beginning of the semester.

- Course instructors should consider ways to reward students with low \% matching and/or punish students with high \% matching on their assignments, according to SafeAssign or TurnItIn. The course instructors should also have a clear explanation on levels of \% matching presenting level of good, average, and poor performance. For example, $0-20 \%$ is good, $21-30 \%$ is average, $31-40 \%$ is poor, and above $41 \%$ is failure.

- Educators should not limit themselves with only technologies offered from the schools. There are many applications and website that provide free services in encouraging interaction and feedback between instructors-students or among classmates.

- Further research may focus on evaluating more student identification systems and lockdown browser software that highly contribute to academic integrity and quality assurance to support online distance learning in higher education and business training environments.

\section{Appendix}
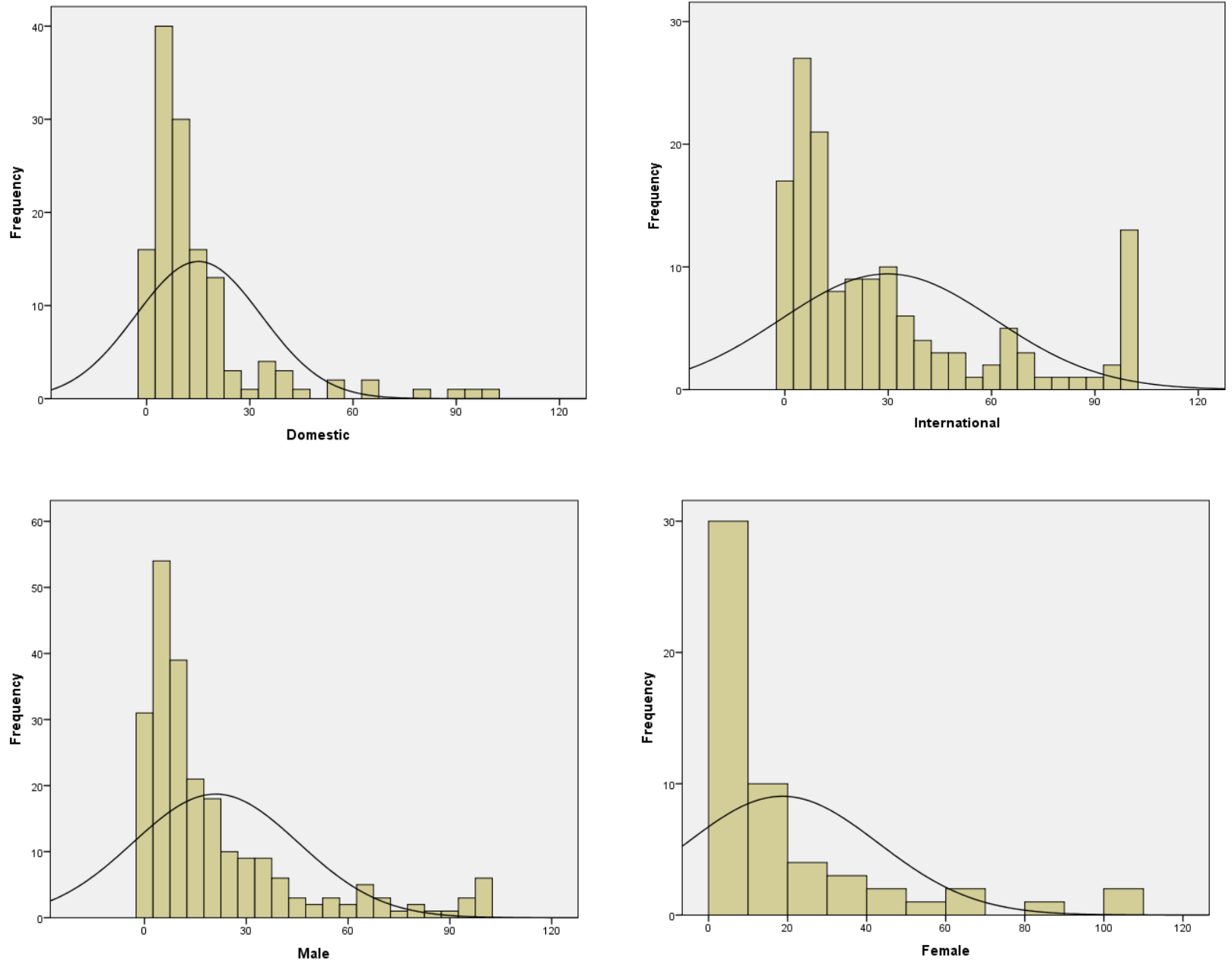

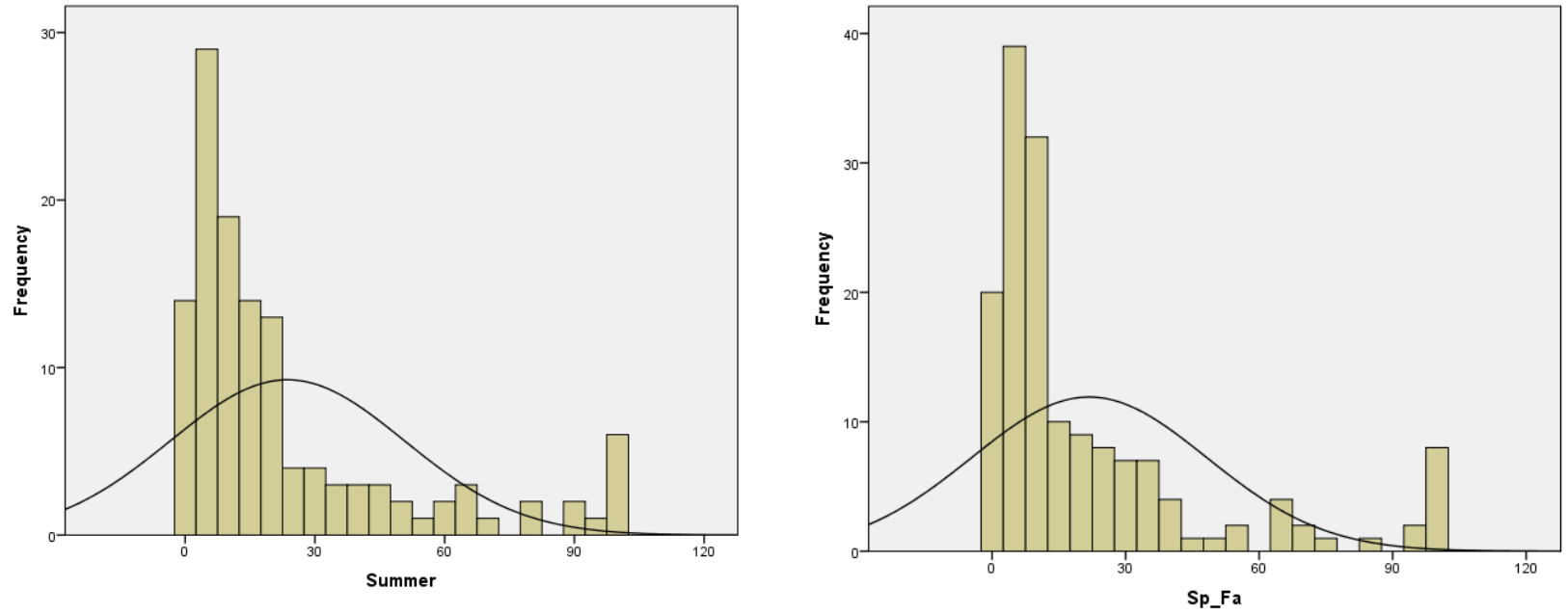

Histogram: Frequency of number of papers for 6 target population.

\section{References}

[1] International Center for Academic Integrity. (2012). Statistics: Overview. Retrieve from the website: http://www.academicintegrity.org/icai/integrity-3.php

[2] Higher Education Opportunity Act. (2008). Retrieved from the website: http://frwebgate.access.gpo.gov/cgi-in/getdoc.cgi?dbname=110_cong_publiclaws\&docid=f:publ315.1 10

[3] Bailie, J. L., \& Jortberg, M. A. (2009, June). Online learner authentication: Verifying the identity of online users. MERLOT Journal of Online Learning and Testing, 5(2), 1-8.

[4] Online Colleges. (2013, August). Online student verification: Is that you? Are you there? Retrieve from the website: http://www.onlinecollege.org/2013/08/16/online-student-verification-is-that-you-are-you-there/

[5] Heussner, K. M. (2012, November). 5 ways online education can keep its students honest. Retrieve from the website: https://gigaom.com/2012/11/17/5-ways-online-education-can-keep-its-students-honest/

[6] Robin. (2015, December). Best practices for academic integrity in online and blended courses. Retrieved from the website: https://www.unthsc.edu/center-for-innovative-learning/best-practices-for-academic-integrity-in-onli ne-and-blended-courses/

[7] Wells, J. T. (1997). Occupational Fraud and Abuse. Obsidian Publishing Co: Austin, TX.

[8] Becker, D., Connolly, J., Lentz, P., \& Morrison, J. (2006). Using the business fraud triangle to predict academic dishonesty among business students. Academy of Educational Leadership Journal, 10(1), 37-54.

[9] King, C. G., Guyette, R. W., \& Piotrowski, C. (2009). Online exams and cheating: An empirical analysis of business students' views. The Journal of Educators Online, 6(1).

[10] Rodchua, S., Yiadom-Boakye, G. \& Woolsey, R. (2011). Student verification system for online assessments: Bolstering quality and integrity of distance learning. Journal of Industrial Technology, 27(3), 1-8.

[11] Webwire. (2009, July). Fifteen hundred college exams proctored live online.

[12] Moore, G. (May, 2010). ProctorCam betting on e-learning upswing. Retrieved from the website: http://www.masshightech.com/stories/2010/05/10/daily29-ProctorCam-betting-on-e-learningupswing.html 
[13] Case, R., \& Cabalka, P. (2009). Remote proctoring: Results of a pilot program at western governors university. Retrieved from the website: http://www.uwex.edu/disted/conference/Resource_library/proceedings/09_19933.pdf

[14] Wikipedia. (2010). Biometrics. Retrieved from the website: http:// en.wikipedia.org/wiki/Biometrics

[15]Epstein, J. (2007, July). Competing the catch plagiarizers. Retrieve from the website: https://www.insidehighered.com/news/2007/07/10/plagiarism

[16] Respondus, Inc. (2017). LockDown browser. Retrieved from the website: http://www.respondus.com/products/lockdown-browser/

[17] Wikepedia.org. (2017). TurnItIn. Retrieved the website: fromhttps://en.wikipedia.org/wiki/TurnItIn

[18] Florida Atlantic University. (2016). Plagiarism prevention: SafeAssign and TurnItIn. Retrieved from the website: https://www.fau.edu/oit/blackboard/safeassign.php

[19] Respondus, Inc. (2017). LockDown Browser-Pricing. Retrieved from the website: http://www.respondus.com/products/lockdown-browser/pricing.shtml

[20] Kioware. (2017). Touch screen kiosk software. Retrieved from the website: http://www.kioware.com/productoverview.aspx

[21] Kioware. (2017). Purchase kiosk Software. Retrieved from the website: http://www.kioware.com/purchase.aspx

[22] Blackboard, Inc. (2017). SafeAssign. Retrieve from the website: https://en-us.help.blackboard.com/ Learn/Administrator/Hosting/Tools Management/SafeAssign

[23] Brady, C., \& Jones, D. (2013). Best practices for authenticating student identity online. Retrieve from the website: http://www.learninghouse.com/blog/training/authenticating-student-identity-online-best-practices

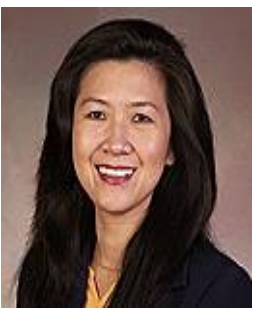

Suhansa Rodchua is an associate professor in industrial management and technology programs at University of Central Missouri, USA. Prior to her PhD in technology management from Indiana State University, she worked as an assistant project manager and cost analyst in consulting and textile industry. She also published books and articles in quality costs in manufacturing and effective teaching tools for distance learning. Dr. Rodchua also certified Project Management Professional (PMI-PMP), Quality Manager/Organizational Excellence (ASQ-CMQ/OE), and Technology Manager (ATMAE-CTM). 